\title{
Real Time Control of a Flexible Joint Manipulator Using Interval Type-2 Fuzzy Logic Controller
}

\author{
Ethem Kelekci, Selcuk Kizir \\ Department of Mechatronics Engineering, Faculty of Engineering, Kocaeli University \\ Kocaeli, Turkey \\ ethem.kelekci@kocaeli.edu.tr, selcuk.kizir@kocaeli.edu.tr
}

\begin{abstract}
Flexible manipulators have several benefits over the rigid manipulators such as light weight with higher payload, better maneuverability, higher operational speed, lower energy consumption. Along these advantages, however, the flexible manipulators cause vibrations and trajectory tracking control problems. In this study, a cascade interval type-2 fuzzy logic controller (IT2FL-C) was proposed for real time trajectory and vibration control of a flexible joint manipulator. The proposed controller was implemented in the system using dSpace DS1103 real-time control board. The cascade control structure includes three separate IT2FL-C. The IT2FL-Cs were designed on the IT2FL-C toolbox, which we developed, with interval triangular membership functions (MFs), Mamdani's fuzzy inference method and Karnik-Mendel (KM) type reduction (TR) algorithm. Several experiments conducted for observation of the proposed IT2FL-C's performance. The step and sinusoidal trajectories were applied to the system changing link length with/without external payload. Additionally, performance of the proposed controllers was compared to conventional type-1 fuzzy logic controller (T1FL-C).
\end{abstract}

Keywords: Flexible Joint, Flexible Manipulator, Interval Membership Functions, Interval Type-2 Fuzzy Logic, Real Time Control.

\section{Introduction}

In today's industry, light-weight robots with a high payload capacity is preferred instead of rigid manipulators. The rigid manipulators have negative impact because of the weight of rigid materials, payload capacity and energy efficiency whereas flexible manipulators cause link deflection (vibration) and position errors. However, convenient control approaches overcome these negative efficiencies of the flexible manipulators. In the literature, for the control of flexible link and flexible joint manipulators, various model based and model free control methods such as Proportional-IntegralDerivative (PID) [1], Linear Quadratic Regulator (LQR) and Linear Quadratic Gaussian (LQG) [2], fuzzy logic [3], [4], a distributed higher-order differential feedback controller [5], intelligent proportional-integral (iP) [6] have been presented. The mathematical model of the flexible manipulators is difficult to obtain because of computationally difficult parameters such as system frictions, moments of inertia and nonlinear behavior of the flexible structures. In this study, therefore, the IT2FL, which is model-free control method, was used for the control of a flexible joint manipulator. The IT2FL presented as an extension of conventional type-1 fuzzy logic have been applied in various control applications. Firdaus and Tokhi [7][8] studied on IT2FL-C for the control of a quadcopter. El-Bardini and El-Nagar [8], [9] carried out IT2FL-C for real time and simulation based control of an inverted pendulum system. Lu and Liu [10] proposed PID type IT2FL-C for trajectory tracking control of a delta robot. Huang and Wang[11] have presented type-2 fuzzy iterative learning control based on IT2FL-C for the control of a Stewart platform. Phuong and Shin [12] proposed a control structure with training algorithm related to IT2FL-C for modeling unstructured uncertainties and estimation of undefined dynamics. In this study cascade IT2FL-C was presented for real time control of a flexible joint manipulator. The cascade control structure compromises three separate IT2FL-C. Each IT2FL-C was designed on the IT2FL-C toolbox, which we developed. And dSpace DS1103 real-time control board was used to implement proposed controller in the system. The paper is organized as follows: Section 2 presents the structure of the IT2FL. Section 3 presents experimental setup of the flexible joint manipulator. Real time control of the flexible joint manipulator using proposed controller and experimental results are presented in Section 4. The overall conclusions are given in Section 5. 


\section{Interval Type-2 Fuzzy Logic Systems}

The structure of the type-2 fuzzy logic system depicted in Fig. 1 is similar to its T1 counterpart [13]. The type- 2 fuzzy sets have interval $[0,1]$ membership grade, whereas membership grades in type-1 fuzzy set are a crisp value.

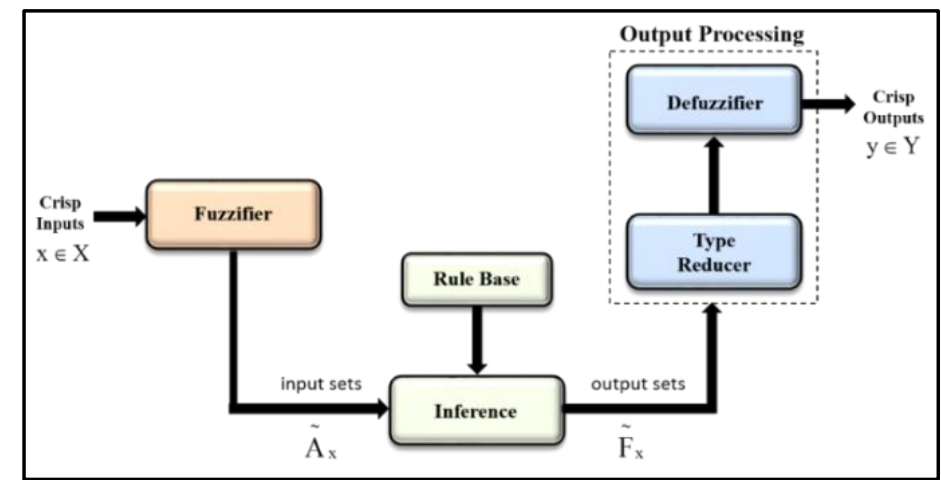

Fig. 1: The structure of the type-2 fuzzy logic system.

A general type-2 fuzzy set denoted as $\widetilde{\mathrm{A}}$ is characterized by $\mu_{\widetilde{\mathrm{A}}}(\mathrm{x}, \mathrm{u})$ where $\mathrm{x} \in \mathrm{X}$ and $\mathrm{u} \in \mathrm{J}_{\mathrm{X}}^{\mathrm{u}} \subseteq[0,1]$ in which $0 \leq \mu_{\widetilde{A}}(\mathrm{x}, \mathrm{u}) \leq 1$, that is $[14]$,

$$
\widetilde{\mathrm{A}}=\mathrm{x}, \mathrm{u},\left(\mu_{\widetilde{\mathrm{A}}}(\mathrm{x}, \mathrm{u})\right) \mid \forall \mathrm{x} \in \mathrm{X}, \forall \mathrm{u} \in \mathrm{J}_{\mathrm{x}}^{\mathrm{u}} \subseteq[0,1]
$$

In equation $1, J_{\mathrm{x}}$ is the primary membership function and $\mu_{\widetilde{\mathrm{A}}}(\mathrm{x}, \mathrm{u})$ is grade of secondary membership function [15]. Type-2 fuzzy sets are called as footprint of uncertainty (FOU). FOU is a closed region remaining between upper and lower membership functions (MF) denoted as, $\left(\bar{\mu}_{\widetilde{\mathrm{A}}}(\mathrm{x}), \underline{\mu}_{\widetilde{\mathrm{A}}}(\mathrm{x})\right)$ respectively. If secondary grade of a FOU is equal to $1, \widetilde{\mathrm{A}}$ is called an interval type-2 fuzzy set, which is also studied in this paper. The general type-2 fuzzy set $(\widetilde{\mathrm{A}})$ in equation 1 can be transformed to;

$$
\widetilde{\mathrm{A}}=\int_{\mathrm{x} \in \mathrm{X}} \int_{\mathrm{u} \in \mathrm{J}_{\mathrm{X}}} 1 /(\mathrm{x}, \mathrm{u})=\int_{\mathrm{x} \in \mathrm{X}}[1 / \mathrm{u}] / \mathrm{x}, \mathrm{J}_{\mathrm{x}} \subseteq[0,1]
$$

Rule form in the IT2FL-S is similar to T1FL-S. However, interval type-2 fuzzy sets include upper and lower MF and therefore, rules are considered using $\underline{\mathrm{f}}^{\mathrm{x}}$ and $\overline{\mathrm{f}}^{\mathrm{x}}$ called upper / lower firing intervals respectively. Inference process using "min" operators for two antecedents and single-consequent is implemented such that [16];

$$
\mathrm{R}^{\mathrm{x}} \rightarrow\left[\underline{\mathrm{f}}^{\mathrm{x}}, \overline{\mathrm{f}}^{\mathrm{x}}\right]=\left[\min \left[\underline{\mu}_{\widetilde{\mathrm{A}}}\left(\mathrm{x}_{1}, \mathrm{u}\right), \underline{\mu_{\widetilde{\mathrm{B}}}}\left(\mathrm{x}_{2}, \mathrm{u}\right)\right], \min \left[\bar{\mu}_{\widetilde{\mathrm{A}}}\left(\mathrm{x}_{1}, \mathrm{u}\right), \bar{\mu}_{\widetilde{\mathrm{B}}}\left(\mathrm{x}_{2}, \mathrm{u}\right)\right]\right]
$$

Moreover, extra type-reduction (TR) process, which transforms type-2 fuzzy set into a type-1 fuzzy set, is required before defuzzification in the IT2FL-S. In the literature several type reduction methods have been proposed. In this study, center-of-sets (COS) TR methods was used with Karnik-Mandel algorithm as defined mathematically in Equation 4 [16].

$$
\mathrm{U}_{\cos }(\mathrm{x})=\bigcup_{\substack{\mathrm{u}_{\mathrm{n}} \in\left[\mathrm{a}^{\mathrm{n}}, \mathrm{b}^{\mathrm{n}}\right] \\ \mathrm{w}_{\mathrm{n}} \in\left[\mathrm{f}_{\mathrm{n}}(\mathrm{x}), \mathrm{f}^{\mathrm{n}}(\mathrm{x})\right]}} \frac{\sum_{\mathrm{n}=1}^{\mathrm{k}} \mathrm{u}_{\mathrm{n}} \mathrm{w}_{\mathrm{n}}}{\sum_{\mathrm{n}=1}^{\mathrm{k}} \mathrm{w}_{\mathrm{n}}}=\left[\mathrm{u}_{1}, \mathrm{u}_{\mathrm{r}}\right]
$$

where $\mathrm{u}_{1}$ and $\mathrm{u}_{\mathrm{r}}$ defined as: 


$$
\begin{aligned}
& \mathrm{u}_{1}=\min _{\mathrm{k} \in[1, \mathrm{~N}-1]} \frac{\sum_{\mathrm{n}=1}^{\mathrm{k}} \mathrm{f}^{-\mathrm{n}} \mathrm{a}^{\mathrm{n}}+\sum_{\mathrm{n}=\mathrm{k}+1}^{\mathrm{N}} \mathrm{f}_{\mathrm{n}} \mathrm{a}^{\mathrm{n}}}{\sum_{\mathrm{n}=1}^{\mathrm{k}} \mathrm{f}^{\mathrm{n}}+\sum_{\mathrm{n}=\mathrm{k}+1}^{\mathrm{N}}{ }_{-\mathrm{n}}^{\mathrm{f}}} \equiv \frac{\sum_{\mathrm{n}=1}^{\mathrm{L}} \mathrm{f}^{-\mathrm{n}} \mathrm{a}^{\mathrm{n}}+\sum_{\mathrm{n}=\mathrm{L}+1}^{\mathrm{N}} \mathrm{f}_{\mathrm{n}} \mathrm{a}^{\mathrm{n}}}{\sum_{\mathrm{n}=1}^{\mathrm{L}} \mathrm{f}^{-\mathrm{n}}+\sum_{\mathrm{n}=\mathrm{k}+1}^{\mathrm{N}}{ }_{-\mathrm{n}}^{\mathrm{f}}}
\end{aligned}
$$

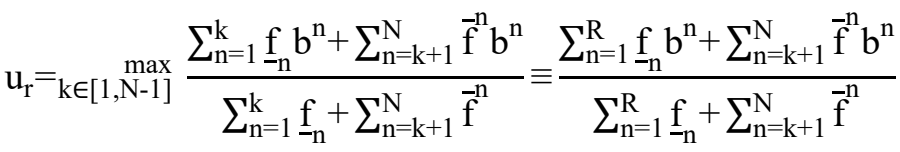

$\mathrm{L}$ and $\mathrm{R}$ variables seen in the equations (5-6) are left and right switch points of each consequent FOU. $\mathrm{a}^{\mathrm{n}}$ and $\mathrm{b}^{\mathrm{n}}$ variables are left and right centroid values obtained by COS method. Finally, $\mathrm{f}^{\mathrm{n}}$ and $\mathrm{f}_{\mathrm{n}}$ are upper and lower firing interval values. Defuzzification process is very simple after finding $\mathrm{u}_{\mathrm{l}}$ and $\mathrm{u}_{\mathrm{r}}$. It is computed as follows:

$$
\mathrm{u}=\frac{\mathrm{u}_{1}+\mathrm{u}_{\mathrm{r}}}{2}
$$

\section{Experimental Setup of the Flexible Joint Manipulator}

The experimental setup of the flexible joint manipulator (Fig. 2(a).) consist of 36W, $111 \mathrm{nNm}$ Faulhaber BLDC (brushless direct current) motor with Faulhaber Mcbl 5004 motor driver, a rotary frame connected the BLDC Motor, a single link attached to springs used for joint flexibility, and two encoders that measure the rotary frame position $(\theta)$ and link deflection $(\alpha)$ as indicated in Fig. 2(b). The angle of rotary frame is measured with an encoder with 512 ppr (pulse per revolution) added behind the BLDC motor. Because of the 246:1 planet gear attached to the motor, number of pulses received the encoder rise to 125952 pulses. Deflection angle of the link is measured by a 2000 ppr encoder with $0.18^{\circ}$ accuracy. The link consists of two parts in order to change the length of the link $(40 \mathrm{~cm}$ and $58 \mathrm{~cm})$.

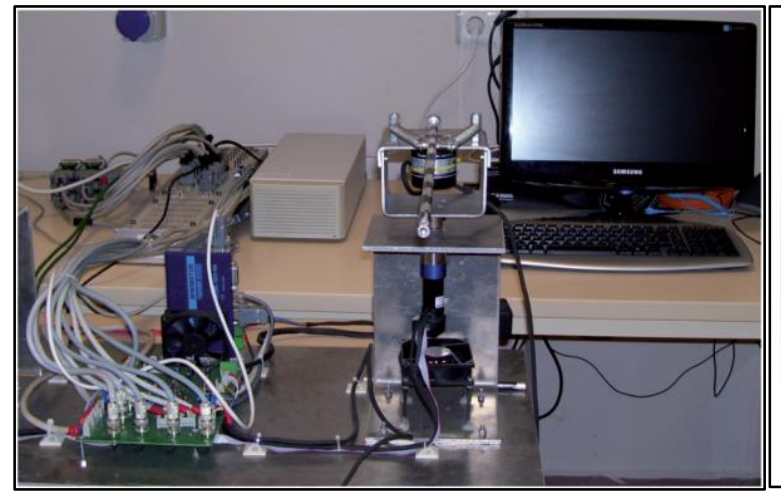

(a)

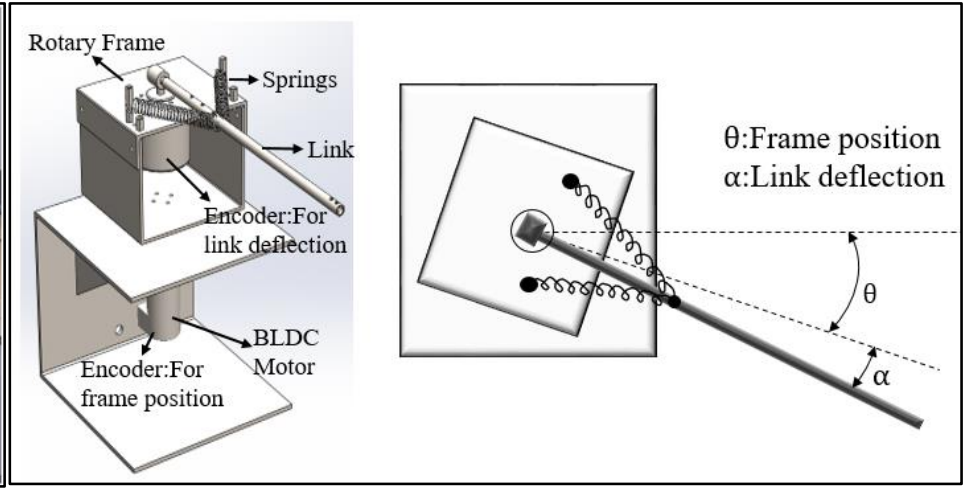

(b)

Fig. 2: a) Experimental setup b) 2d/3d model of the flexible Joint manipulator.

\section{Real Time Control of the Flexible Joint Manipulator}

\subsection{Design of the Cascade IT2FL-C}

Applied cascade IT2FL-C for the control of the flexible joint robot manipulator is depicted in Fig. 3. The cascade control structure includes three IT2FL-C related to frame rotation angle $(\theta)$, link deflection $(\alpha)$ and their combinations. In the first controller called Theta, theta error $\left(\theta_{\mathrm{e}}\right)$ and its derivative $\left(\dot{\theta}_{\mathrm{e}}\right)$ are the inputs, similarly alpha error $\left(\alpha_{\mathrm{e}}\right)$ and its derivative $\left(\dot{\alpha}_{\mathrm{e}}\right)$ are the inputs of the second controller called Alpha. The last controller generates control signal of the system using outputs of the other controllers $(\theta, \alpha)$. Interval MFs and rules related to all controllers have been designed based on type-1 MFs exist in [17]. All IT2FL-C was designed on our interval type-2 fuzzy logic toolbox as shown in Fig. 4 according to the rules in Table 1. 


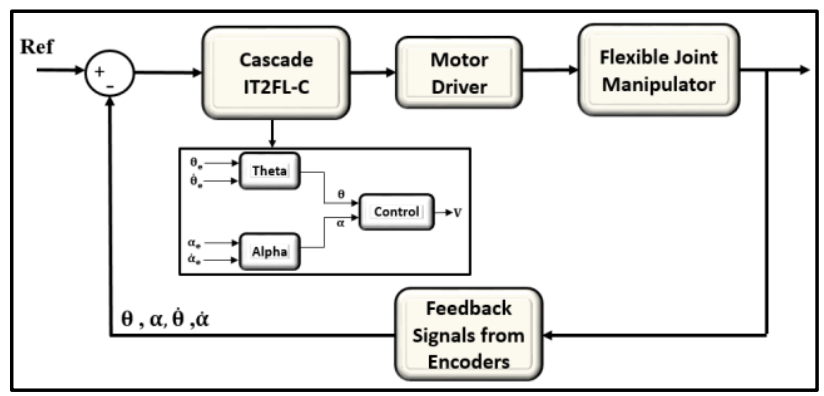

Fig. 3: Control structure of the flexible joint manipulator.

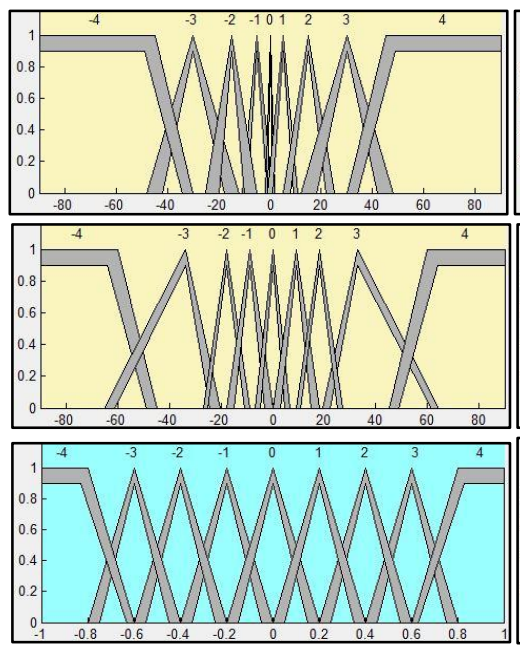

(a)

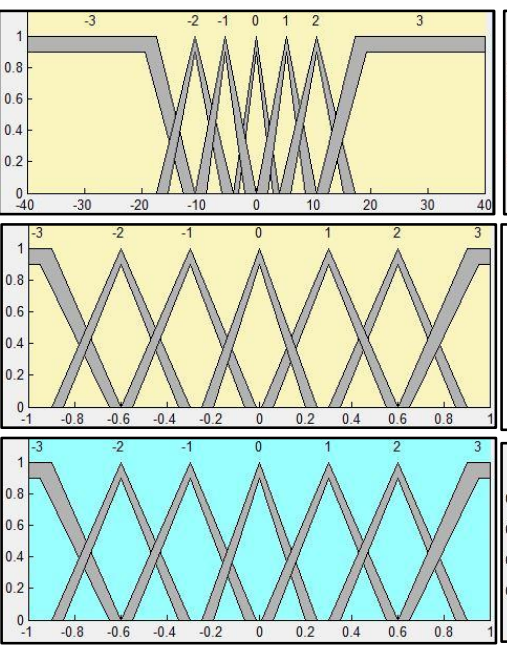

(b)
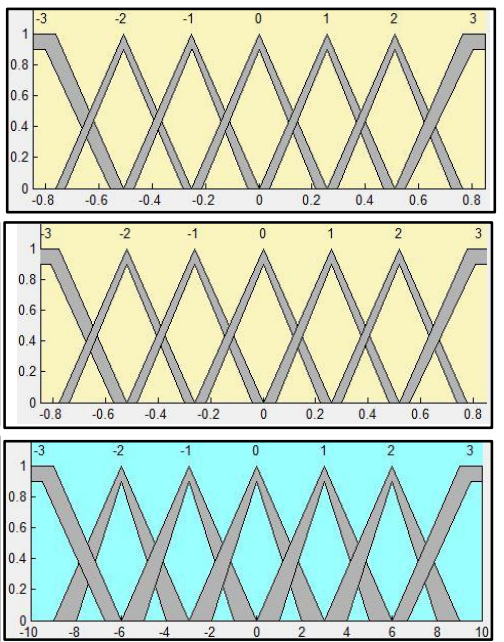

(c)

Fig. 4: MFs of the a) first IT2FL-C related to $\theta$ b) second IT2FL-C related to $\alpha$ ) last IT2FL-C related to combination of $\theta$ and $\alpha$.

Table 1: The rule tables related to a) first controller b) second controller c) last controller.

\begin{tabular}{|c|c|c|c|c|c|c|c|c|c|c|c|c|c|c|c|c|c|c|c|c|c|c|c|c|c|c|c|c|}
\hline & \multicolumn{9}{|c|}{ Position Error $\left(\boldsymbol{\theta}_{\mathrm{e}}\right)$} & & & \multicolumn{7}{|c|}{ Deflection Error $\left(\alpha_{\mathrm{e}}\right)$} & & & \multicolumn{7}{|c|}{ Output of first controller $(\theta)$} \\
\hline \multirow{8}{*}{ 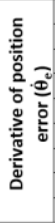 } & -4 & 4 & 4 & 4 & 3 & 3 & 2 & 2 & 1 & 0 & & & -3 & -2 & -1 & 0 & 1 & 2 & 3 & & & -3 & -2 & -1 & 0 & 1 & 2 & 3 \\
\hline & -3 & 4 & 4 & 3 & 2 & 3 & 2 & 1 & 0 & -1 & \multirow{7}{*}{ 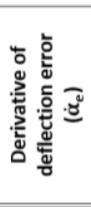 } & -3 & 3 & 3 & 2 & 2 & 1 & 1 & 0 & \multirow{7}{*}{ 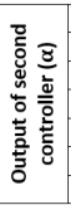 } & -3 & -3 & -3 & -3 & -2 & -2 & -1 & 0 \\
\hline & -2 & 4 & 3 & 3 & 2 & 2 & 1 & 0 & -1 & -2 & & -2 & 3 & 2 & 2 & 1 & 1 & 0 & -1 & & -2 & -3 & -3 & -2 & -2 & -1 & 0 & 1 \\
\hline & -1 & 3 & 3 & 2 & 1 & 1 & 0 & -1 & -2 & -2 & & -1 & 2 & 2 & 1 & 1 & 0 & -1 & -1 & & -1 & -3 & -2 & -2 & -1 & 0 & 1 & 2 \\
\hline & 0 & 3 & 2 & 2 & 1 & 0 & -1 & -2 & -2 & -3 & & 0 & 2 & 1 & 1 & 0 & -1 & -1 & -2 & & 0 & -2 & -1 & 0 & 0 & 0 & 1 & 2 \\
\hline & $\begin{array}{l}1 \\
2\end{array}$ & $\frac{2}{2}$ & $\frac{2}{1}$ & $\begin{array}{l}1 \\
0\end{array}$ & $\frac{0}{-1}$ & $\begin{array}{l}-1 \\
-2\end{array}$ & $\begin{array}{l}-1 \\
-2\end{array}$ & $\begin{array}{l}-2 \\
-3\end{array}$ & $\begin{array}{l}-3 \\
-3\end{array}$ & $\begin{array}{l}-3 \\
-4\end{array}$ & & 1 & 1 & 1 & 0 & -1 & -1 & -2 & -2 & & 1 & -2 & -1 & 0 & 1 & 2 & 2 & 3 \\
\hline & 3 & 1 & 0 & -1 & -2 & -3 & -2 & -3 & -4 & -4 & & 2 & 1 & 0 & -1 & -1 & -2 & -2 & -3 & & 2 & -1 & 0 & 1 & 2 & 2 & 3 & 3 \\
\hline & 4 & 0 & -1 & -2 & -2 & -3 & -3 & -4 & -4 & -4 & & 3 & 0 & -1 & -1 & -2 & -2 & -3 & -3 & & 3 & 0 & 1 & 2 & 2 & 3 & 3 & 3 \\
\hline
\end{tabular}

In real time applications, the integration of dSpace software and Matlab provides simplicity to implement the developed controller in Simulink environment. However, necessary dScpace blocks must be defined in Simulink environment as shown in Fig. 5. Simulink block diagrams can be seamlessly transferred to dSpace Simulator (ControlDesk) via code generated from Simulink Coder and dSpace Real-Time Interface. In measurement block, the rotary frame position and link deflection values were received by dSpace incremental encoder interfaces and their derivatives were computed. The value of encoders and their derivatives transferred to input Block for determination of error signals. These error signals were utilized in proposed cascade IT2FL-C block and control signals were generated for motor motion. 


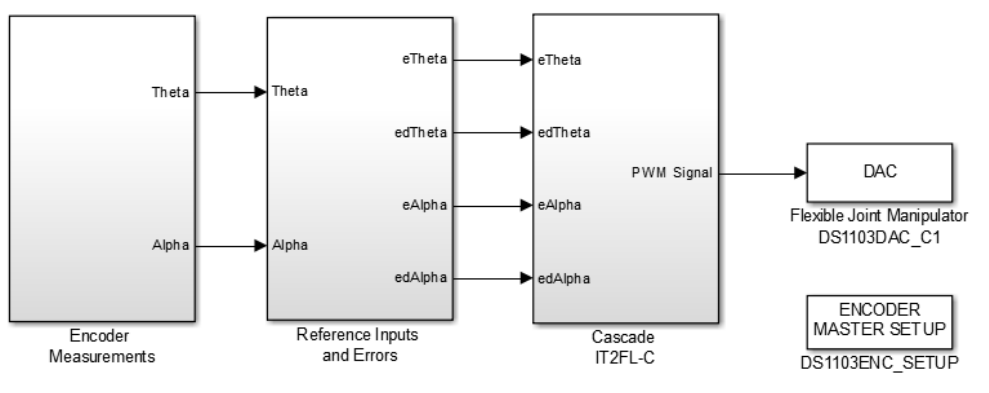

Fig. 5: Real-time implementation of controllers using dSpace DS1103 control board.

\subsection{Experimental Results}

In this section, the step and sinusoidal trajectories were applied to the flexible joint system changing link length and with/without external payload. To display the visual indications of the control performance, the root mean squared error (RMSE), mean squared error (MSE) and mean absolute error (MAE) were used as defined in equation (8).

$$
\mathbf{R M S E}=\sqrt{\frac{1}{\mathrm{~N}} \sum_{\mathrm{i}=1}^{\mathrm{N}}(\mathrm{e}(\mathrm{t}))^{2}}, \mathbf{M S E}=\frac{1}{\mathrm{~N}} \sum_{\mathrm{i}=1}^{\mathrm{N}}(\mathrm{e}(\mathrm{t}))^{2}, \mathbf{M A E}=\frac{1}{\mathrm{~N}} \sum_{\mathrm{i}=1}^{\mathrm{N}}|\mathrm{e}(\mathrm{t})|
$$

In the step trajectory shown in Fig. 6(a), reference inputs were changed as $0^{\circ}$ to $90^{\circ}, 90^{\circ}$ to $0^{\circ}$ and $0^{\circ}$ to $-90^{\circ}$. Positon $(\theta)$ errors in Fig. 6b) and deflection $(\alpha)$ error in Fig. 6(c) indicate rotary frame position errors and link deflection errors respectively. In accordance with the RMSE, MSE and MAE values of the position errors in Table 2, it is seen that the performances of the controllers are almost similar for short link length $(40 \mathrm{~cm})$. However, link deflection errors in Table 2 show that performance of the proposed IT2FL-C (peak value:2.9 ${ }^{\circ}$ ) is better than T1FL-C (peak value:3.9 ${ }^{\circ}$.
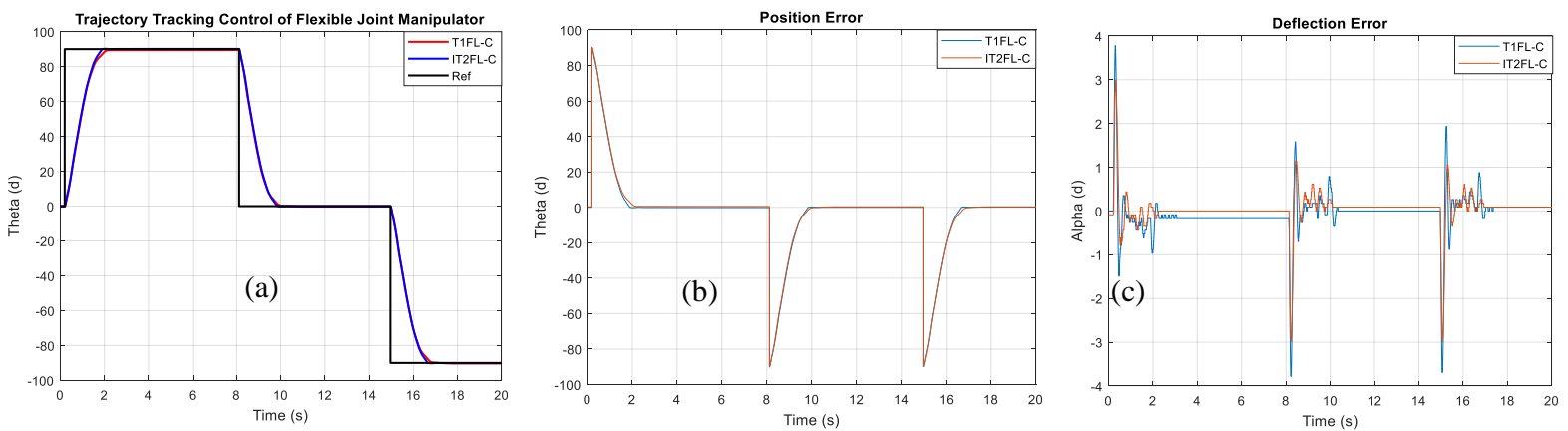

Fig. 6: Step trajectory tracking of the flexible joint manipulator (link length:40cm).

Table 3: The performance comparison of the controllers for step trajectory.

\begin{tabular}{|l|l|c|c|c|c|c|c|}
\hline \multicolumn{2}{|c|}{} & \multicolumn{3}{|c|}{ Position Error } & \multicolumn{3}{c|}{ Deflection Error } \\
\cline { 3 - 8 } \multicolumn{2}{|c|}{ Link: 40cm } & TMSE & MSE & MAE & RMSE & MSE & MAE \\
\cline { 2 - 7 } & IT2FL-C & 0.16517 & 5.45682 & 9.67233 & 0.00361 & 0.26052 & 0.22211 \\
\hline \multirow{2}{*}{ Link: 58cm } & T1FL-C & 0.17803 & 5.44718 & 9.34296 & 0.00299 & 0.17890 & 0.16952 \\
\cline { 2 - 8 } & IT2FL-C & 0.17448 & 6.33709 & 10.55306 & 0.00728 & 1.06106 & 0.45918 \\
\hline
\end{tabular}

Link length of the system was changed as $58 \mathrm{~cm}$ to test performance of the controllers under the effect of different inertia. Step responses of the controllers with long link $(58 \mathrm{~cm})$ were depicted in Fig. 7 (a-b). In this experiment, positon 
errors of both controllers increased slightly compared to short link results in Table 2. Longer link increased the system inertia and thus more link deflection errors were occurred. However, IT2FL-C was less affected by increased inertia compared to T1FL-C.
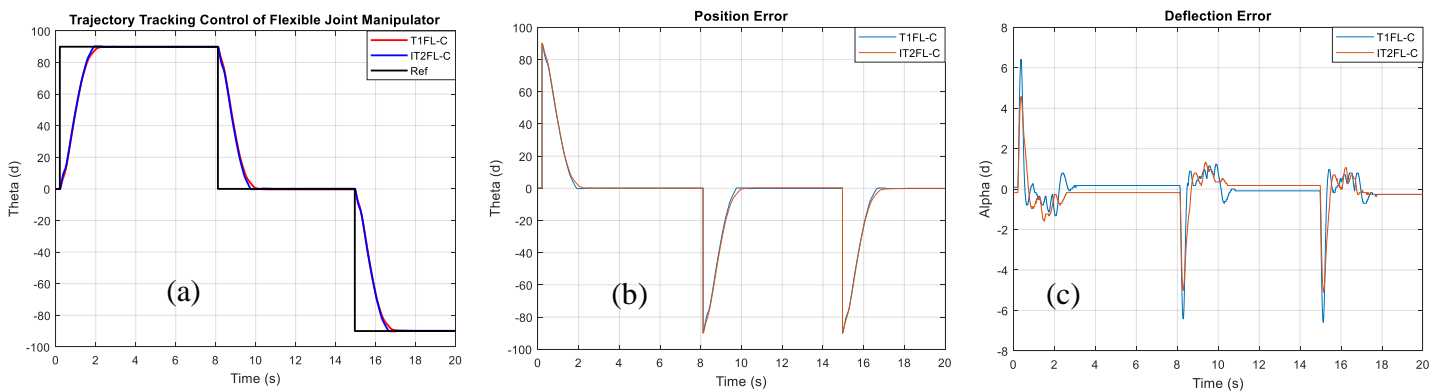

Fig. 7: Step trajectory tracking of the flexible joint manipulator (link length:58cm).

The experiment of the sinusoidal trajectory tracking is depicted in Fig. 8. Amplitude of the sin function was increased along the trajectory as shown in Fig. 8(a). The sinusoidal trajectory was followed by two controllers almost with similar performance for short link as seen in Table 3 and in Fig. 8(a-b). However, RMSE, MSE and MAE values of the link deflection errors for T1FL-C is two times more than IT2FL-C approximately. Also, in Fig. 8(c), it is seen that deflection errors of the T1FL-C (peak value:1.75 ) are more than IT2FL-C (peak value:0.6 ${ }^{\circ}$ ). Similarly, the sinusoidal trajectory tracking control of the system using long link were performed by two controllers (Fig. 9(a)). In this experiment, position error of the IT2FL-C was almost unchanged (\%1.5) compared to short link experiment, whereas position error of the T1FL-C (\%10) increased significantly as seen in Table 3.
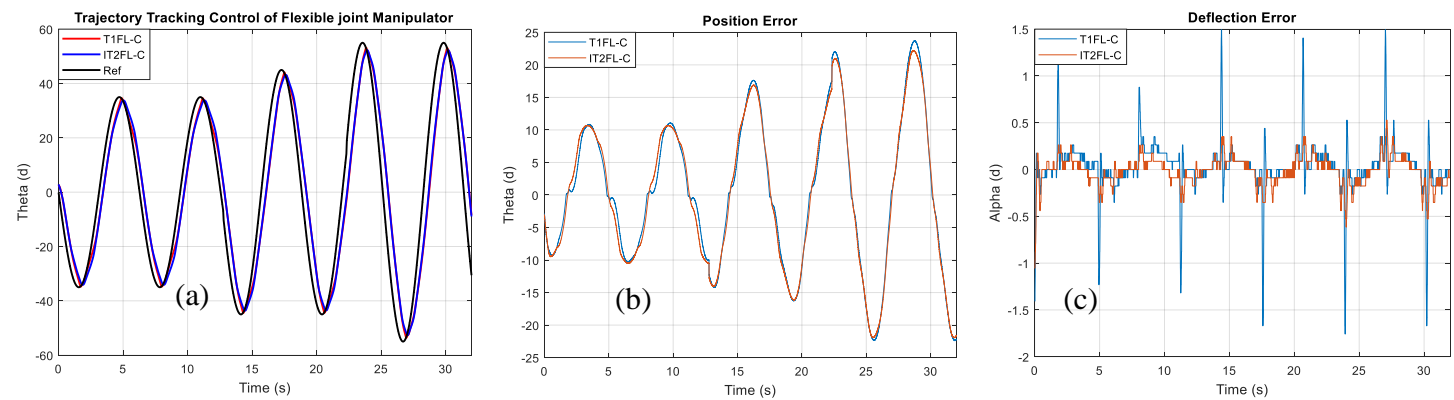

Fig. 8: Sinusoidal trajectory tracking of the flexible joint manipulator (link length:40cm).

Table 3: The performance comparison of the controllers for sinusoidal trajectory.

\begin{tabular}{|c|c|c|c|c|c|c|c|}
\hline & \multicolumn{3}{|c|}{ Position Error } & \multicolumn{3}{|c|}{ Deflection Error } \\
\hline & & RMSE & MSE & MAE & RMSE & MSE & MAE \\
\hline \multirow{2}{*}{ Link: $40 \mathrm{~cm}$} & T1FL-C & 0.06372 & 1.29916 & 9.79607 & 0.00152 & 0.07428 & 0.14302 \\
\hline & IT2FL-C & 0.06357 & 1.29320 & 9.34544 & 0.00087 & 0.02438 & 0.10810 \\
\hline \multirow{2}{*}{ Link: $58 \mathrm{~cm}$} & T1FL-C & 0.07049 & 1.59011 & 10.59901 & 0.00378 & 0.45769 & 0.42939 \\
\hline & IT2FL-C & 0.06416 & 1.31745 & 9.86037 & 0.00298 & 0.28339 & 0.37839 \\
\hline
\end{tabular}



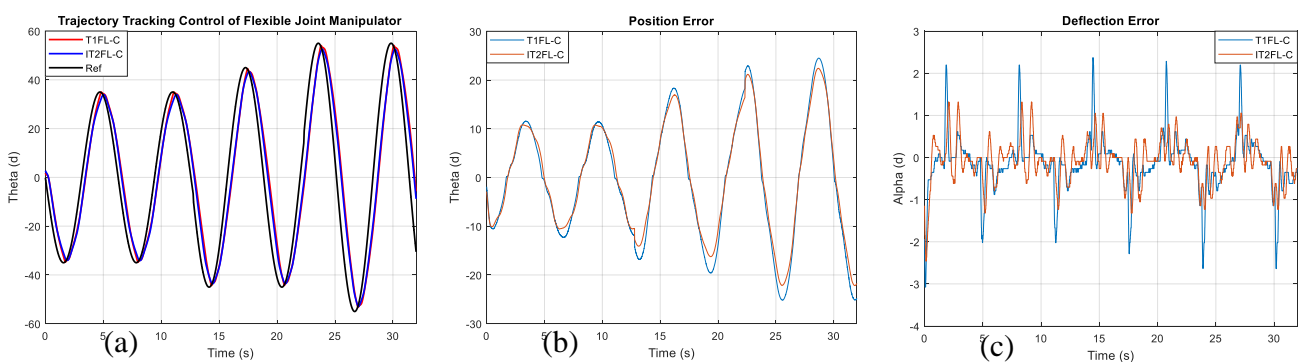

Fig. 9: Sinusoidal trajectory tracking of the flexible joint manipulator (link length:58cm).

It has been explored that type-2 fuzzy logic are effective and convenient controlling method under the effect of uncertainties if compared to type-1 fuzzy logic. In order to show performance of the controllers with these effects, the external payload (50gr) was attached to the link. In step response, overshoot (\%8) was occurred on frame positon as seen in Fig.10(a-b) for both controllers because of payload. RMSE, MSE and MAE values of the link deflection errors in Table 3 and also maximum deflection errors of T1FL-C and IT2FL-C, which were $11^{\circ}$ and $7^{\circ}$ respectively (Fig. 10(c)), showed proposed controller better than T1FL-C.
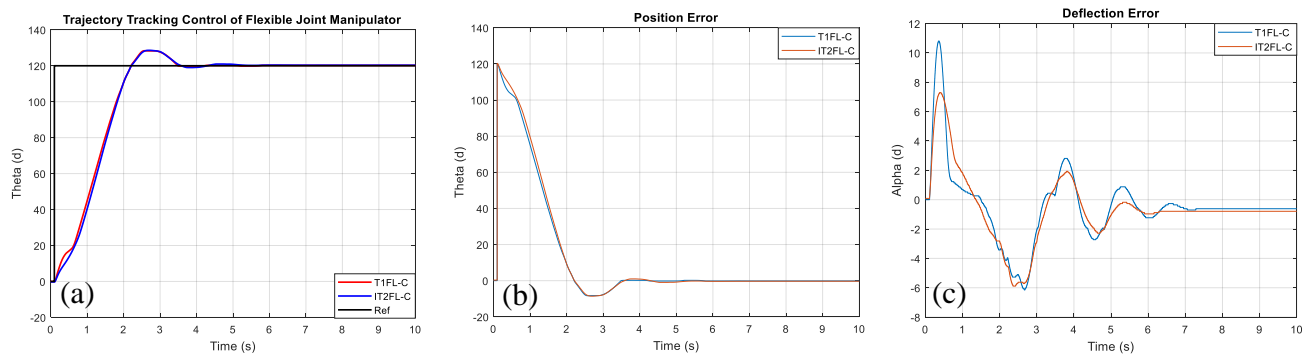

Fig. 10: Step trajectory tracking of the flexible joint manipulator (link length:58cm, payload:50gr).

Table 3: The performance comparison of the controllers for step and sinusoidal trajectory with payload.

\begin{tabular}{|c|l|l|l|l|l|l|l|}
\hline \multicolumn{2}{|c|}{} & \multicolumn{3}{|c|}{ Position Error } & \multicolumn{3}{c|}{ Deflection Error } \\
\cline { 3 - 8 } \multicolumn{2}{|c|}{} & RMSE & MSE & MAE & \multicolumn{1}{c|}{ RMSE } & MSE & MAE \\
\hline \multirow{2}{*}{$\begin{array}{c}\text { Step } \\
\text { Trajectory }\end{array}$} & T1FL-C & 0.34639 & 1.19998 & 14.69223 & 0.02517 & 6.33570 & 1.57852 \\
\cline { 2 - 8 } & IT2FL-C & 0.33367 & 1.11344 & 13.96582 & 0.02378 & 5.65398 & 1.67281 \\
\hline $\begin{array}{c}\text { Sinusoidal } \\
\text { Trajectory }\end{array}$ & T1FL-C & 0.07836 & 2.08755 & 12.91447 & 0.01161 & 4.31674 & 1.59468 \\
\cline { 2 - 8 } & IT2FL-C & 0.06194 & 1.30445 & 9.96643 & 0.01126 & 4.06051 & 1.68882 \\
\hline
\end{tabular}

The experiment of the sinusoidal trajectory with long link and external payload is depicted in Fig. 11(a). In Table 3, it is seen that position error of the T1FL-C was more than IT2FL-C (Fig. 11(b)), while deflection errors of the both controllers were almost similar (Fig. 11(c))
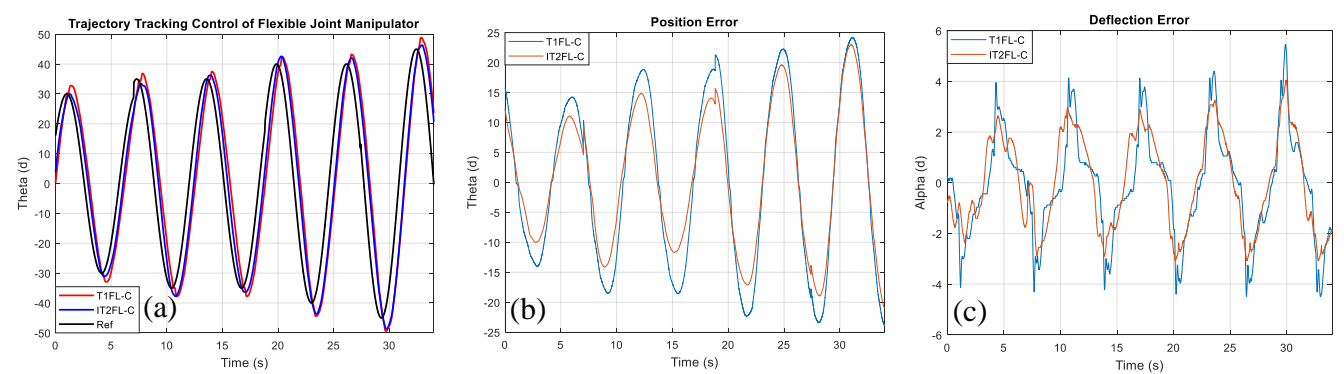

Fig. 11: Sinusoidal trajectory tracking of the flexible joint manipulator (link length:58cm payload:50gr). 


\section{Conclusion}

In this paper, a cascade interval type-2 fuzzy logic controller was proposed for a real time trajectory and vibration control of a flexible joint manipulator. The structure of the proposed controller was designed using our interval type-2 fuzzy logic toolbox, and it was implemented in the system using dSpace DS1103 real-time control board. In order to observe the performance of the controller, several experiments were conducted in normal case with different link length and under the effect of external payload. Also, the performance of the proposed controller was compared with the conventional type-1 fuzzy logic controller. In step responses of the system using both short and long link, position errors of the controllers were almost similar. In addition, link deflection errors showed that the performance of the proposed controller was better. In sinusoidal experiments, the trajectories were followed similarly by two controllers for short link, while frame position errors of the system controlled by type-1 controller with long link increased importantly compared to type-2. Furthermore, link deflections of type-1 controller were bigger than type- 2 along all sinusoidal trajectories. With the external payload, the overshoot was seen on frame position for both controllers in step trajectory. However, proposed controller was less affected by payload according to RMSE, MSE and MAE values of the position and link deflection errors. Similarly, performance of the proposed interval type-2 fuzzy logic controller for the experiment of the sinusoidal trajectory with long link and external payload was found to be better than conventional type-1 fuzzy logic controller.

\section{References}

[1] M. T. Ho and Y. W. Tu, "PID controller design for a flexible-link manipulator," Proc. 44th IEEE Conf. Decis. Control. Eur. Control Conf. CDC-ECC '05, vol. 2005, pp. 6841-6846, 2005.

[2] Z. M. Doina, "LQG / LQR Optimal Control for Flexible Joint Manipulator," no. Epe, pp. 25-27, 2012.

[3] V. G. Moudgal, W. A. Kwong, K. M. Passino, and S. Yurkovich, "Fuzzy learning control for a flexible-link robot," IEEE Trans. Fuzzy Syst., vol. 3, no. 2, pp. 199-210, 1995.

[4] M. a. Ahmad, R. M. T. R. Ismail, M. S. Ramli, M. a. Zawawi, and M. H. Suid, "Vibration control strategy for flexible joint manipulator: A Fuzzy Logic Control approach,” 2010 IEEE Symp. Ind. Electron. Appl., no. Isiea, pp. 469-474, 2010.

[5] J. T. Agee, Z. Bingul, and S. Kizir, "Trajectory and Vibration Control of a Single-link Flexible Joint Manipulator Using a Distributed Higher Order Differential Feedback Controller,” J. Dyn. Syst. Meas. Control, no. April, 2017.

[6] J. T. Agee, S. Kizir, and Z. Bingul, "Intelligent proportional-integral (iPI) control of a single link flexible joint manipulator," JVC/Journal Vib. Control, vol. 21, no. 11, pp. 2273-2288, 2015.

[7] A. R. Firdaus and M. O. Tokhi, "Sliding mode control - Based interval type-II fuzzy logic controller for quadcopter UAVs," 18th Int. Conf. Climbing Walk. Robot., pp. 1-8, 2015.

[8] A. M. El-Nagar, M. El-Bardini, and N. M. El-Rabaie, "Intelligent control for nonlinear inverted pendulum based on interval type-2 fuzzy PD controller," Alexandria Eng. J., vol. 53, no. 1, pp. 23-32, 2014.

[9] M. El-Bardini and A. M. El-Nagar, "Interval type-2 fuzzy PID controller for uncertain nonlinear inverted pendulum system," ISA Trans., vol. 53, no. 3, pp. 732-743, 2014.

[10] X. Lu and M. Liu, "Optimal Design and Tuning of PID-Type Interval Type-2 Fuzzy Logic Controllers for Delta Parallel Robots," Int. J. Adv. Robot. Syst., vol. 13, no. 3, 2016.

[11] C. I. Huang and R. S. Wang, "Hybrid control based on type-2 fuzzy-iterative learning control strategies with stewart platform for repetitive trajectories," 2015 10th Asian Control Conf. Emerg. Control Tech. a Sustain. World, ASCC 2015, 2015.

[12] P. D. Ngo and Y. C. Shin, "Modeling of unstructured uncertainties and robust controlling of nonlinear dynamic systems based on type-2 fuzzy basis function networks," Eng. Appl. Artif. Intell., vol. 53, pp. 74-85, 2016.

[13] A. Taskin and T. Kumbasar, "An Open Source Matlab/Simulink Toolbox for Interval Type-2 Fuzzy Logic Systems," 2015 IEEE Symp. Ser. Comput. Intell., pp. 1561-1568, 2015.

[14] J. M. Mendel, R. I. John, and F. Liu, "Interval Type-2 Fuzzy Logic Systems Made Simple," Fuzzy Syst. IEEE Trans., vol. 14, no. 6, pp. 808-821, 2006.

[15] A. D. Torshizi, M. H. F. Zarandi, and H. Zakeri, "On type-reduction of type-2 fuzzy sets: A review," Appl. Soft Comput. J., vol. 27, pp. 614-627, 2015.

[16] H. H. Jerry M. Mendel, William Melek, Woei-Wan Tan, Hao Ying, Introduction to type-2 fuzzy logic control: 
theory and applications. Southern California., 2014.

[17] I. H. Akyüz, Z. Bingül, and S. Kizir, "Cascade fuzzy logic control of a single-link flexible-joint manipulator," Turkish J. Electr. Eng. Comput. Sci., vol. 20, no. 5, pp. 713-726, 2012. 